\title{
Three-Dimensional Coculture Model to Analyze the Cross Talk Between Endothelial and Smooth Muscle Cells
}

\author{
Minu Karthika Ganesan, MSc, ${ }^{1, *}$ Richard Finsterwalder, MSc, ${ }^{1, *}$ Heide Leb, PhD, Ulrike Resch, PhD, \\ Karin Neumüller, BSc, Rainer de Martin, $\mathrm{PhD}^{2}$, and Peter Petzelbauer, MD ${ }^{1}$
}

The response of blood vessels to physiological and pathological stimuli partly depends on the cross talk between endothelial cells (EC) lining the luminal side and smooth muscle cells (SMC) building the inner part of the vascular wall. Thus, the in vitro analysis of the pathophysiology of blood vessels requires coculture systems of EC and SMC. We have developed and validated a modified three-dimensional sandwich coculture (3D SW-CC) of EC and SMC using open $\mu$-Slides with a thin glass bottom allowing direct imaging. The culture dish comprises an intermediate plate to minimize the meniscus resulting in homogenous cell distribution. Human umbilical artery SMC were sandwiched between coatings of rat tail collagen I. Following SMC quiescence, human umbilical vein EC were seeded on top of SMC and cultivated until confluence. By day 7, EC had formed a confluent monolayer and continuous vascular endothelial (VE)-cadherin-positive cell/cell contacts. Below, spindle-shaped SMC had formed parallel bundles and showed increased calponin expression compared to day 1. EC and SMC were interspaced by a matrix consisting of laminin, collagen IV, and perlecan. Basal messenger RNA (mRNA) expression levels of E-selectin, angiopoietin-1, calponin, and intercellular adhesion molecule 1 (ICAM-1) of the 3D SW-CC was comparable to that of a freshly isolated mouse inferior vena cava. Addition of tumor necrosis factor alpha (TNF $\alpha$ ) to the 3D SW-CC induced Eselectin and ICAM-1 mRNA and protein induction, comparable to the EC and SMC monolayers. In contrast, the addition of activated platelets induced a significantly delayed but more pronounced activation in the 3D SW-CC compared to EC and SMC monolayers. Thus, this 3D SW-CC permits analyzing the cross talk between EC and SMC that mediate cellular quiescence as well as the response to complex activation signals.

Keywords: 3D model, coculture, cross talk, endothelial cells, extracellular matrix, platelets, smooth muscle cells

\section{Introduction}

$\mathbf{T}$ HE TUNICA INTIMA of arteries and veins consists of a monolayer of endothelial cells (EC) resting on a basal membrane and a stratum subendotheliale and is separated from the tunica media by the internal elastic membrane. The stratum subendotheliale, also called lamina propria intimae, consists of loose connective tissue intermingled with smooth muscle cells (SMC). In adult vasculature, SMC are in a contractile state (i.e., quiescent/nonproliferating) and form direct contacts with EC. ${ }^{1,2}$ Under physiological conditions, the quiescent state of cells within the vessel wall is maintained by diffusible and contact-dependent signals between the cells and their extracellular matrix. ${ }^{3}$ For example, angiopoietin 1 , secreted mainly by vascular SMC, binds and activates tie2, a transmembrane receptor tyrosine kinase, expressed on EC surface, which then activates akt, a cell survival kinase, thereby aiding in the maintenance of vascular quiescence. ${ }^{4-6}$ These EC-SMC interactions are also important during angiogenesis. SMC recruited by $\mathrm{EC}^{7}$ stabilize the newly formed vascular wall by rendering quiescence and by producing extracellular matrix. Other cellular mediators involved in EC-SMC signaling leading to vessel wall maturation, survival, and quiescence are vascular endothelial growth factor $\mathrm{A},{ }^{8}$ transforming growth factor- $\beta$ (TGF- $\beta$ ), ${ }^{9}$ and endothelial differentiation sphingolipid G-

\footnotetext{
${ }^{1}$ Skin and Endothelium Research Division (SERD), Department of Dermatology, Medical University of Vienna, Vienna, Austria.

${ }^{2}$ Department of Vascular Biology and Thrombosis Research, Medical University of Vienna, Vienna, Austria.

*Both these authors contributed equally to this work.

(C) Minu Karthika Ganesan et al., 2017; Published by Mary Ann Liebert, Inc. This Open Access article is distributed under the terms of the Creative Commons Attribution Noncommercial License (http://creativecommons.org/licenses/by-nc/4.0/) which permits any noncommercial use, distribution, and reproduction in any medium, provided the original author(s) and the source are credited.
} 
protein-coupled receptor-1. ${ }^{10}$ Thus, EC-SMC signaling is crucial for maintaining the vascular tone and it's functionality in vivo.

An example of a disturbed cross talk between EC and SMC resulting in vessel wall pathology comes from vascular bypass surgery ${ }^{11}$ or stenting. ${ }^{12}$ As an adverse event of this procedure, the stratum subendotheliale may become enlarged, mainly due to EC dysfunction ${ }^{13}$ and phenotype change of the SMC from contractile to secretory/proliferative. ${ }^{14}$ This phenomenon is called intimal hyperplasia and causes lumen narrowing and subsequently reocclusion of the grafted vessel. ${ }^{15}$ Hence, to study the pathological cross talk between EC and $\mathrm{SMC}$ in vitro, it is important to create a quiescent EC-SMC coculture which can be activated in a controlled environment. EC-SMC cocultures must overcome several obstacles. SMC require serum starvation to acquire a contractile phenotype, while EC require serum to proliferate and form a uniform monolayer. A secretory SMC phenotype prevents $\mathrm{EC}$ monolayer formation, and a confluent EC monolayer is required to keep SMC in a contractile state. ${ }^{16}$ Several EC-SMC cocultures have been described. EC directly cultivated on SMC, ${ }^{17}$ cocultures on opposite sides of a transwell membrane, ${ }^{18}$ culture of EC on collagen gels containing SMC, ${ }^{19}$ and spheroid-bound EC/SMC cocultures. ${ }^{20}$ In most cases, the morphology and orientation of cells within the cocultures, the formation of an extracellular matrix, and the basal expression of activation and quiescence markers were not systematically analyzed. In the current study, we have developed and validated a modified three-dimensional sandwich coculture (3D SW-CC) using human umbilical artery SMC and human umbilical vein EC.

\section{Materials and Methods}

\section{Cells and tissue}

Human umbilical vein EC were isolated from umbilical cords as described, ${ }^{21}$ grown in Iscove's Modified Dulbecco's Medium (GIBCO, Paisley, United Kingdom) containing 20\% fetal calf serum (GIBCO) and EC growth supplement $(50 \mu \mathrm{g} /$ $\mathrm{mL}$; PromoCell) and used between passages 2 and 4. Human umbilical artery SMC were isolated from the umbilical cord arteries using a modified protocol. ${ }^{22}$ Briefly, umbilical arteries were stripped of the surrounding Wharton's jelly, dissected longitudinally, cut into small pieces, and placed with their luminal side facing down on a Petri dish coated with $1 \%$ gelatin. Pieces were covered with growth medium (PromoCell) supplemented with $10 \%$ fetal calf serum (GIBCO) and a supplement mix (PromoCell) consisting of $0.5 \mathrm{ng} / \mathrm{mL}$ recombinant human epidermal growth factor, $2 \mathrm{ng} / \mathrm{mL}$ recombinant human basic fibroblast growth factor, and $5 \mu \mathrm{g} / \mathrm{mL}$ recombinant human insulin. Outgrowing cells were subpassaged and used between passages 4 and 6 .

Inferior vena cava (IVC) were taken from 12-week-old male C57BL/6J mice following anesthesia with isoflurane and cervical dislocation and processed immediately.

\section{Isolation of rat tail collagen I}

The technique was described previously. ${ }^{23}$ Briefly, following removal of the rat tail skin, each second vertebra was broken; the tendons were extracted and placed in ethanol. Following air-drying, they were placed in $0.1 \%$ acetic acid and centrifuged at $4^{\circ} \mathrm{C}$ at $17000 \mathrm{~g}$ for $1 \mathrm{~h}$. Supernatants containing the clear acid extracted collagen I (as verified by western blotting, data not shown) were aliquoted and stored at $-20^{\circ} \mathrm{C}$.

\section{Cell culture}

$\mathrm{EC}, \mathrm{SMC}$, as well as the cocultures were grown in $\mu$-Slide 4 Well ${ }^{\mathrm{Ph}+}$ slides (Ibidi) coated with rat tail collagen I. Rat tail collagen I was polymerized as described. ${ }^{24}$ Briefly, $1 \mathrm{~mL}$ of rat tail collagen I was mixed with $125 \mu \mathrm{L}$ of $10 \times$ M199 (Sigma, St. Louis, MO) by pipetting on ice, until the solution turned yellow. To this, $125 \mu \mathrm{L}$ of reconstitution buffer $(2.2 \mathrm{~g} \mathrm{NaHCO} 3$ in $100 \mathrm{~mL}$ of $0.05 \mathrm{~N} \mathrm{NaOH}$ and $200 \mathrm{mM}$ HEPES) was added, which turned the solution pink. The $\mathrm{pH}$ was adjusted to 7.17.4. $\mu$-Slide $4 \mathrm{Well}{ }^{\mathrm{Ph}+}$ slides were placed on ice and coated with ice cold collagen I solution. Excess fluid was aspirated by a pipette. The slides were then incubated at $37^{\circ} \mathrm{C}$ for $30 \mathrm{~min}$ to allow collagen I polymerization.

For the 3D SW-CC, SMC (100,000 cells) suspended in $700 \mu \mathrm{L}$ of SMC growth medium were seeded on top of the collagen I coating and incubated at $37^{\circ} \mathrm{C}$ for $45 \mathrm{~min}$. Then, cells were washed using $1 \times$ Dulbecco's phosphate-buffered saline with calcium and magnesium (Lonza, Basel, Switzerland). Adherent SMC were covered with a second coating of collagen I. Following collagen I polymerization, smooth muscle growth medium was added and cells were incubated at $37^{\circ} \mathrm{C}$. On day 3 , the growth medium was replaced with serum-free quiescence medium Dulbecco's modified Eagle's medium F12 (DMEM F12; Invitrogen, Paisley, United Kingdom), containing 1\% insulin-transferrin-selenium (GIBCO), 1\% L-glutamine (Invitrogen), and $1 \%$ Pen Strep (Invitrogen). ${ }^{17}$ On day 5, EC $(150,000$ cells) in $700 \mu \mathrm{L}$ of EC growth medium containing $20 \%$ fetal calf serum were added to the SMC sandwich and incubated at $37^{\circ} \mathrm{C}$ in a cell culture incubator for $48 \mathrm{~h}$. On day 7 , EC growth medium was replaced with CC medium EBM-2 (EC basal medium-2, Clonetics; Lonza) supplemented with $3.3 \%$ fetal calf serum (GIBCO), 1\% Insulin Transferrin Selenium (GIBCO), and Gentamycin (1:200; GIBCO). The 3D SW-CC was then incubated and maintained at $37^{\circ} \mathrm{C}$ in a cell culture incubator with $5 \% \mathrm{CO}_{2}$ for 15-20 days with fresh medium changes every 2 nd day.

EC and SMC were also cocultured in $\mu$-Slide 4 Well ${ }^{\mathrm{Ph}+}$ slides, following the same protocol as above, omitting the collagen I sandwiching step (CC). This CC served as a control for the validation of 3D SW-CC.

\section{Antibodies and reagents}

The following primary antibodies were used: rabbit polyclonal anti-human vascular endothelial (VE)-cadherin (160840, 1:100; Cayman Chemical), mouse monoclonal anti-Heparan Sulfate Proteoglycan 2 (ab23418, 1:100; Abcam), rabbit polyclonal anti-collagen IV (ab6586, 1:200; Abcam), rabbit polyclonal anti-laminin (ab11575, 1:200; Abcam), Pacific Blue ${ }^{\text {TM }}$ human integrin alpha-IIb (CD41) (303714; BioLegend, San Diego, CA), Cy3 labeled mouse monoclonal anti- $\alpha$-smooth muscle actin (clone HIP8, 1:300; Sigma), PE labeled antihuman homing cell adhesion molecule (CD44) (338807; BioLegend), mouse monoclonal anti-intercellular adhesion molecule 1 (ICAM-1) (BBIG-I1, 1:200; R\&D Systems), mouse monoclonal anti-E-selectin (BBA2, 1:100; R\&D Systems), 4',6-diamidino-2-phenylindole (DAPI; D9542, 1:5000; SigmaAldrich), and FITC-conjugated rabbit polyclonal anti-VE- 
Cadherin (ab33321, 1:100; Abcam). Secondary antibodies were as follows: Cy5-labeled goat anti-rabbit IgG (115-175-166, 1:500; Jackson Laboratories), Alexa Fluor 488 goat anti-mouse (A-11001, 1:500; Thermo Fisher), Alexa Fluor 633 goat antimouse (A-21053, 1:500; Thermo Fisher), and Alexa Fluor 488 goat anti-rabbit (A-11034, 1:500; ThermoFisher). ECL plus (Amersham) was used for developing the western blots. For stimulation experiments, human recombinant transforming growth factor-beta1 (TGF- $\beta 1$ ) (240-B-010; R\&D Systems) and recombinant human tumor necrosis factor alpha (TNF $\alpha ; 300$ 01A; PeproTech) were used. For platelet isolation, 3.2\% sodium citrate (BD Biosciences) and $1 \mu \mathrm{M}$ prostaglandin $\mathrm{I} 2$ (Sigma-Aldrich) were used.

\section{Immunofluorescence and confocal microscopy}

In all imaging procedures, cells were directly analyzed within the $\mu$-Slide $4 \mathrm{Well}^{\mathrm{Ph}+}$ slides. Cells were fixed with $4 \%$ paraformaldehyde (PFA) for $20 \mathrm{~min}$ at room temperature, washed (three times) with phosphate-buffered saline (PBS), permeabilized by using $0.5 \%$ Triton-X 100 in PBS for $10 \mathrm{~min}$, rinsed with PBS, and then incubated in PBS containing 2\% bovine serum albumin, $0.1 \%$ (v/v) tween-20 for $1 \mathrm{~h}$. The slides were then incubated with indicated primary antibodies $\left(4^{\circ} \mathrm{C}\right.$, overnight), washed using PBS, followed by incubation with appropriate secondary antibodies ( $1 \mathrm{~h}$, room temperature). Nuclei were stained with DAPI. Cells were then imaged by a confocal laser scanning microscope (LSM-700; Carl Zeiss) using a $20 \times$ lens (numeric aperture 0.8 ) by making $\mathrm{Z}$ stack galleries starting from the bottom of the well reaching the top of the EC layer $(0-20 \mu \mathrm{m})$. Z-stacks were created under the following conditions: The average line scanning number is 4 , and the dimensions are for $x: 1024, y: 1024$, and $z: 10,8$-bit. Spectral bleed through was prevented by sequential scanning of each fluorochrome in separate channels. Orthogonal cuts and 3D reconstruction were made by using the Zen 2.1 lite software.

\section{Western blot}

Three-dimensional SW-CC on days 1, 3, 5, and 7 were lysed in $2 \times$ reduced laemmli buffer, loaded onto a sodium dodecyl sulfate (SDS) gel, electrophoresed, and blotted. Membranes were blocked with $5 \%$ milk in $1 \times$ PBST $(0.1 \%$ $(\mathrm{v} / \mathrm{v})$ Tween 20 in $1 \times \mathrm{PBS})$ followed by incubation with indicated primary and appropriate secondary antibodies. Bound antibodies were visualized by chemiluminescence and exposure to Hyperfilm ECL.

\section{Real-time polymerase chain reaction}

Total RNA was extracted using the RNeasy Mini Kit (Qiagen, Hilden, Germany) and reverse transcribed using the Revert Aid H First Strand cDNA synthesis kit (Fermentas, Life Technologies). Real-time polymerase chain reaction (PCR) primers for human and mouse E-selectin, ICAM-1, calponin, and angiopoietin-1 (FAM primers, Assay on demand) were purchased from Applied Biosystems (Foster City, CA). Reaction mixtures contained $12.5 \mu \mathrm{L}$ of TaqMan Universal PCR Master Mix (Applied Biosystems), 1.25 $\mu \mathrm{L}$ Assay-on-demand, and $1 \mu \mathrm{L}$ of complementary DNA into a total volume of $25 \mu \mathrm{L}$. Cycling parameters were as follows: $50^{\circ} \mathrm{C}$ for $2 \mathrm{~min}, 95^{\circ} \mathrm{C}$ for $10 \mathrm{~min}$, followed by 40 cycles at $95^{\circ} \mathrm{C}$ for $10 \mathrm{~s}$ and $60^{\circ} \mathrm{C}$ for 1 min. Glyceraldehyde-3-phosphate dehydrogenase (GAPDH) for human samples and $\beta-2$ microglobulin (B2M) for mouse samples were used as housekeeping genes. Reactions were run on StepOnePlus real-time polymerase chain reaction (RTPCR) platform, and data analysis was performed with the StepOnePlus Software v2.0 (Applied Biosystems). Messenger RNA (mRNA) concentrations were calculated by subtracting

B
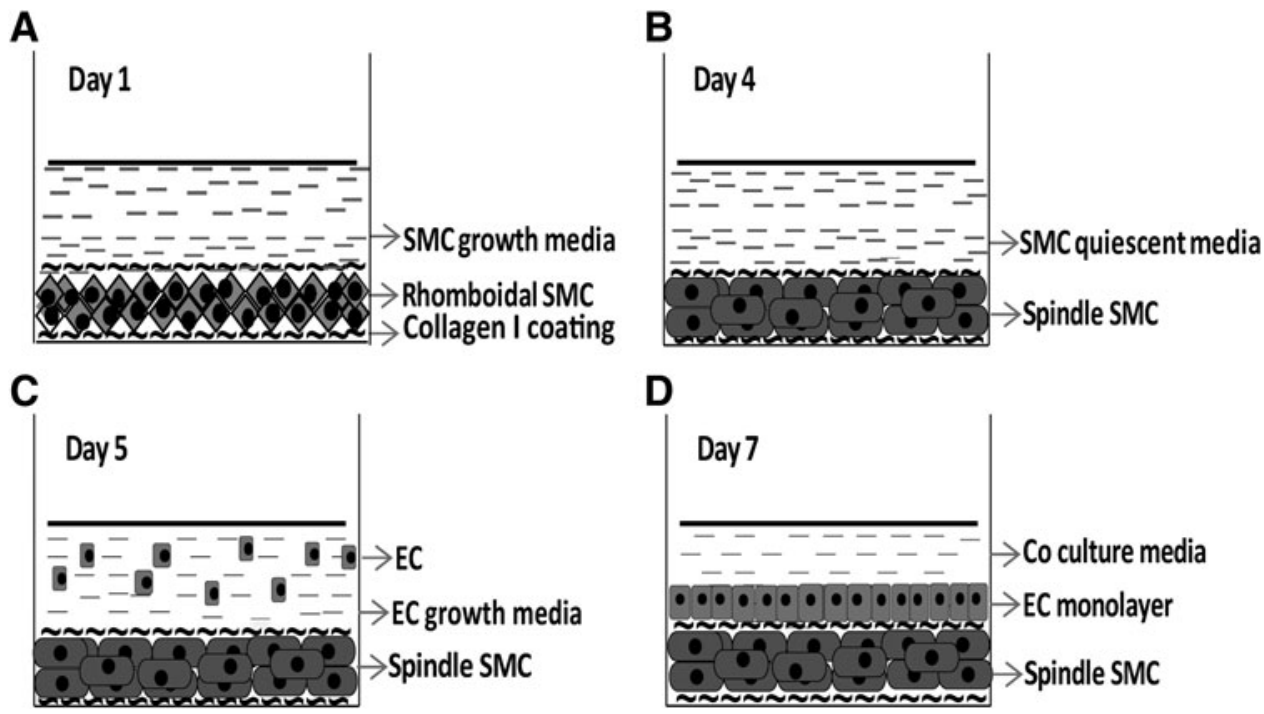

FIG. 1. Experimental setup of the 3D SW-CC. (A) Day 1, the surface of an Ibidi $\mu$-Slide 4 Well ${ }^{\mathrm{Ph}+}$ was coated with rat tail collagen I. Then, $10^{5} \mathrm{SMC} / \mathrm{cm}^{2}$ in SMC growth medium were seeded into each well, allowed to adhere, covered with a second coating of collagen I, and cultivated in SMC growth medium for $48 \mathrm{~h}$ at $37^{\circ} \mathrm{C}$. Then, the growth medium was replaced with serum-free quiescence medium. (B) Day 4 , following $24 \mathrm{~h}$ of serum starvation, SMC acquired a contractile phenotype. (C) Day 5, 1.5 $\times 10^{5} \mathrm{EC}$ in growth medium were seeded on top of SMC-collagen I sandwich and incubated for $48 \mathrm{~h}$ at $37^{\circ} \mathrm{C}$. (D) Day 7, EC growth medium was replaced by coculture medium with $3.3 \%$ FCS. The 3D SW-CC can now be cultured for up to 2 weeks. 3D SW-CC, three-dimensional sandwich coculture; EC, endothelial cells; FCS, fetal calf serum; SMC, smooth muscle cells. 
$C_{\mathrm{T}}$ of the housekeeping gene from $C_{\mathrm{T}}$ of the target gene $\left(\Delta C_{\mathrm{T}}\right)$. The mean of $\Delta C_{\mathrm{T}}$ control was subtracted from the $\Delta C_{\mathrm{T}}$ target gene reaction $\left(\Delta \Delta C_{\mathrm{T}}\right)$ and calculated as $2^{(-\Delta \Delta C \mathrm{~T})}$.

\section{Human platelet isolation}

Human platelets were isolated using the protocol as described. $^{25}$ Briefly, venous blood from a healthy volunteer was collected in $3.2 \%$ sodium citrate and centrifuged at $125 \mathrm{~g}$ for $20 \mathrm{~min}$. The upper third part of the plasma (platelet-rich plasma) was collected and incubated for 5 min with $1 \mu \mathrm{M}$ prostaglandin I2 to inhibit platelet aggregation. Following centrifugation at $3000 \mathrm{~g}$ for $2 \mathrm{~min}$, platelets were washed twice with PBS supplemented with prostaglandin I2 to remove fibrinogen. Platelets were resuspended in PBS, incubated for $25 \mathrm{~min}$ at room temperature to ensure PGI2 consumption, and coincubated with indicated cell cultures at a platelet-to-cell ratio of 100:1.

\section{Statistical analysis}

Statistics was performed by GraphPad Prism 5 (Graph Pad Software, Inc.). Results are calculated as mean \pm SD.
Significance was assessed by one way analysis of variance (ANOVA; Gaussian distribution was verified using Levene's and Bartlett's test), when comparing more than two groups followed by Tukey's multiple comparison post hoc test and Dunnett's post hoc test when groups were compared with a single control. For the stimulation experiments with TNF $\alpha$ and platelets involving different sample groups and time points, two-way ANOVA followed by Bonferroni post hoc test was used $(* p<0.05)$.

\section{Results and Discussion}

\section{Morphology of the 3D SW-CC between days 1 and 7}

Figure 1 schematically describes the procedure to construct a 3D SW-CC of SMC and EC. On day 1, SMC were seeded on collagen I coated Ibidi $\mu$-Slide 4 Well ${ }^{\mathrm{Ph}+}$ slides. Following attachment, they were covered by a second coating of collagen I. After 1 day, SMC were rhomboidal in shape (secretory or proliferative phenotype, Figs. 1A and 2A). On day $4,24 \mathrm{~h}$ following serum starvation, they were spindle shaped. They were tightly packed and aligned in parallel bundles (Figs. 1B and 2A) indicative of contractile
A
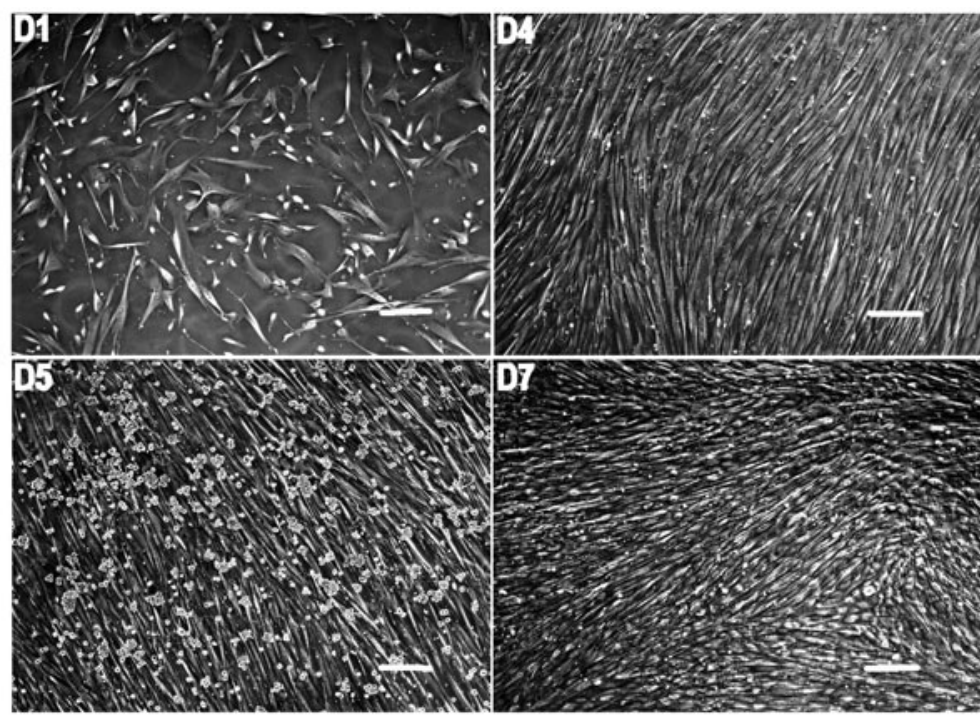

B
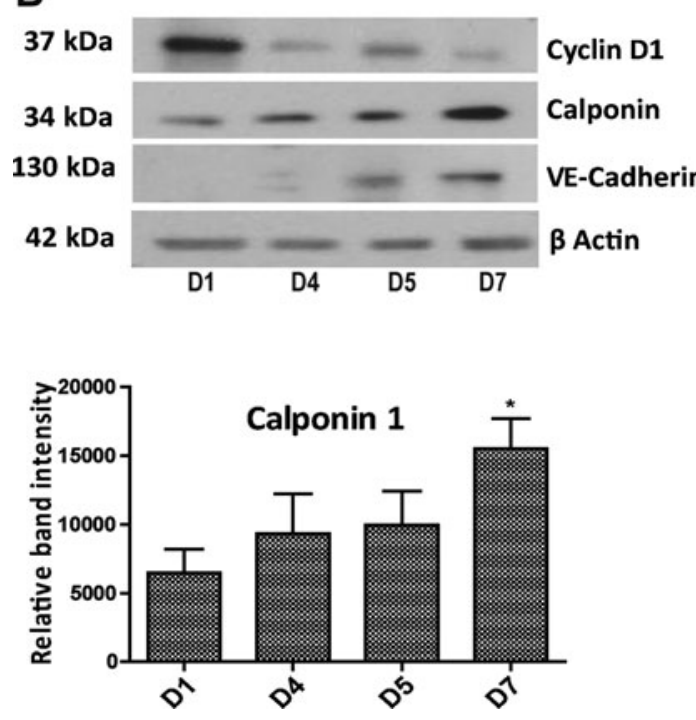
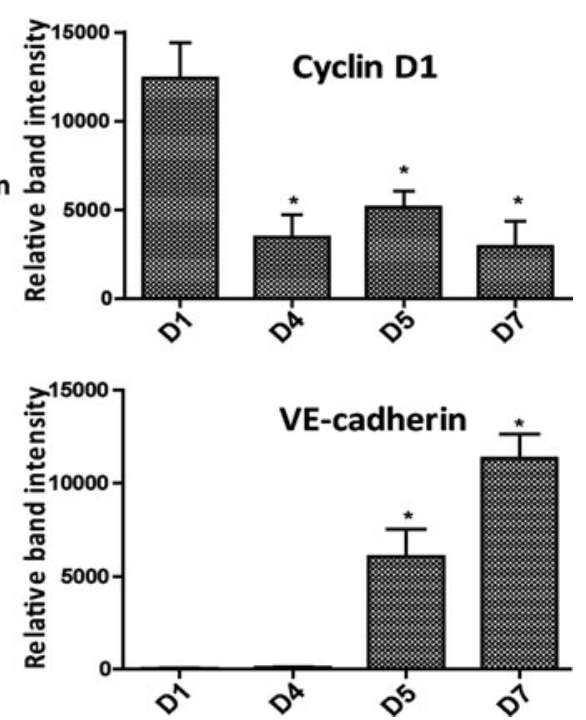

FIG. 2. The 3D SW-CC between days 1 and 7. (A) Phase contrast images, day 1 (D1): secretory SMC, day 4 (D4): contractile SMC, day 5 (D5): EC added on top of SMC, and day 7 (D7): EC monolayer on top of contractile SMC, scale bar $=200$ $\mu \mathrm{m}$. (B) Western blot analysis for cyclin D1, calponin 1, and VE-cadherin protein expression at indicated days. $\beta$-actin served as loading control. Band intensities were normalized to $\beta$-actin. Bar graphs display mean \pm SD. $n=4, * p<0.05$, one way ANOVA with Tukey's multiple comparison post hoc test. ANOVA, analysis of variance; $S D$, standard deviation; VE, vascular endothelial. 
phenotype. ${ }^{26}$ On day 5, following EC seeding, SMC retained their contractile phenotype (Figs. 1C and 2A) despite the fact that the medium now contained serum. This contractile phenotype of SMC is essential, since a secretory phenotype would prevent or disrupt endothelial monolayer formation. ${ }^{16}$ SMC sandwiched between two coatings of collagen I appear to be responsible for this "quiescence" effect. Omitting the top layer of collagen I or mixing SMC with collagen I before seeding activated SMC, when EC were seeded on top (not shown). Collagen I seems to mediate this "quiescence" effect by preventing initial contact formation between SMC and EC at the time of EC seeding. Collagen I, a matrix protein found abundantly within the tunica media of blood vessels, could also directly support a contractile phenotype of the SMC. ${ }^{27}$ On day 7, EC had completely covered the SMC sandwich forming a continuous and uniform monolayer of cobblestoneshaped cells (Figs. 1D and 2A). Of note, the use of an intermediate plate in our 3D SW-CC prevented meniscus formation at the corners of the well. It not only allowed better imaging but also prevented SMC cluster formation and supported an even distribution of cells.

To further characterize the dynamics of this system, we performed western blots to analyze the expression of cyclin D1 (CCND1) as a marker for cell proliferation, ${ }^{28}$ calponin (CNN1) as a marker for SMC differentiation, ${ }^{29}$ and vascular endothelial (VE)-cadherin as an EC marker (Fig. 2B). Beta actin was used as the loading control. Cyclin D1 expression was highest on day 1, confirming the secretory/proliferative phenotype of the SMC, and was significantly reduced on day 4 confirming quiescence of the SMC. The addition of EC on day 5 increased cyclin D1 levels, which were again decreased on day 7 (Fig. 2B). Calponin expression levels of the 3D SW-CC showed a steady increase from day 1 until day 7, reaching highest expression on day 7 , reflecting the phenotype change of SMC from secretory to contractile. VE-cadherin expression increased from day 5 to 7 and confirmed the presence of EC. The quiescence of the SW$\mathrm{CC}$ at day 7 was further confirmed by the Edu cell proliferation assays (Supplementary Fig. S1A; Supplementary Data are available online at www.liebertpub.com/tec). Seeding densities of EC on top of SMC at ratios of 1:1 or 1.5:1 did not change outcomes (Supplementary Fig. S1B). To validate the separation of SMC and EC layers and the uniform distribution of cells, we used cell tracker ${ }^{\mathrm{TM}}$ orange-stained SMC and cell tracker greenstained EC to build and analyze the 3D SW-CC at day 7 by using a confocal microscope. A series of X-Y slices through the 3D SW-CC was scanned from different $Z$ distances starting from the bottom of the well, and a 3D image was generated. Figure 3A exemplifies such a reconstruction. Figure $3 \mathrm{~B}$ provides an orthogonal cut section and demonstrates the separation of SMC and EC layers. Immunofluorescence staining of the 3D SW-CC revealed that the alpha-smooth muscle actin-positive layer of SMC (red) was found approximately between 0 and $7 \mu \mathrm{m}$ and the VE-cadherin-positive layer of EC (green) between 7 and 11. $5 \mu \mathrm{m}$ as measured from the bottom of the well (Fig. 3C and Supplementary Fig. S2A). Importantly, EC formed a uniform network of VE-cadherin-positive cell/cell contacts. Intensity profiles of red ( $\alpha$-smooth muscle actin) and green (VE-cadherin) channels confirmed the clear separation of SMC and EC (Supplementary Fig. S2B). To rule out endothelial-mesenchymal transition (EndMT), SW-CC was stained for CD44 (a surrogate marker for $\mathrm{EndMT}^{30}$ ). SMC monolayers constitutively expressed CD44 while EC monolayers as well as EC in the SW-CC
FIG. 3. Three-dimensional reconstruction of the 3D SW-CC on day 7. (A) Confocal 3D reconstruction of the 3D SW-CC showing two separated cell layers. Before seeding, SMC were stained red with cell tracker ${ }^{\mathrm{TM}}$ orange and EC were stained green with cell tracker green. (B) Orthogonal cut through a Z stack gallery showing EC (loaded with cell tracker green) residing on top of SMC (loaded with cell tracker orange). (C) Representative confocal images from a Z stack gallery at indicated distances from the bottom of the well. The 3D SW-CC was fixed and stained for $\alpha$-smooth muscle actin (red) for SMC and VEcadherin (green) for EC, scale bar $=50 \mu \mathrm{m}$. (D) 3D reconstruction of a $\mathrm{Z}$ stack gallery. Left image: lateral view, right image: anterior view. The 3D SW-CC was fixed and stained for $\alpha$-smooth muscle actin (red) for SMC and VEcadherin (green) for EC, scale bar $=50 \mu \mathrm{m}$.

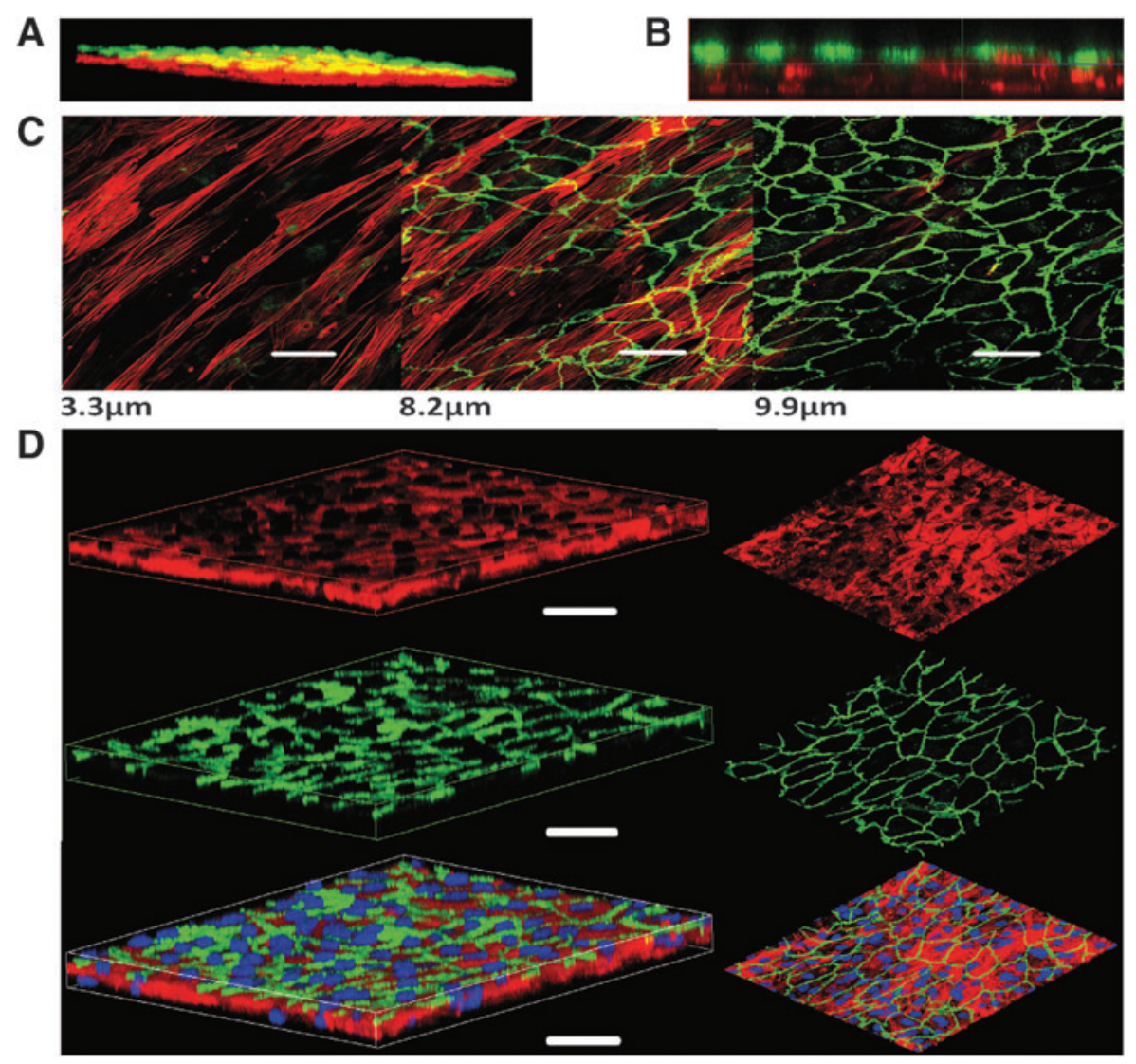


A
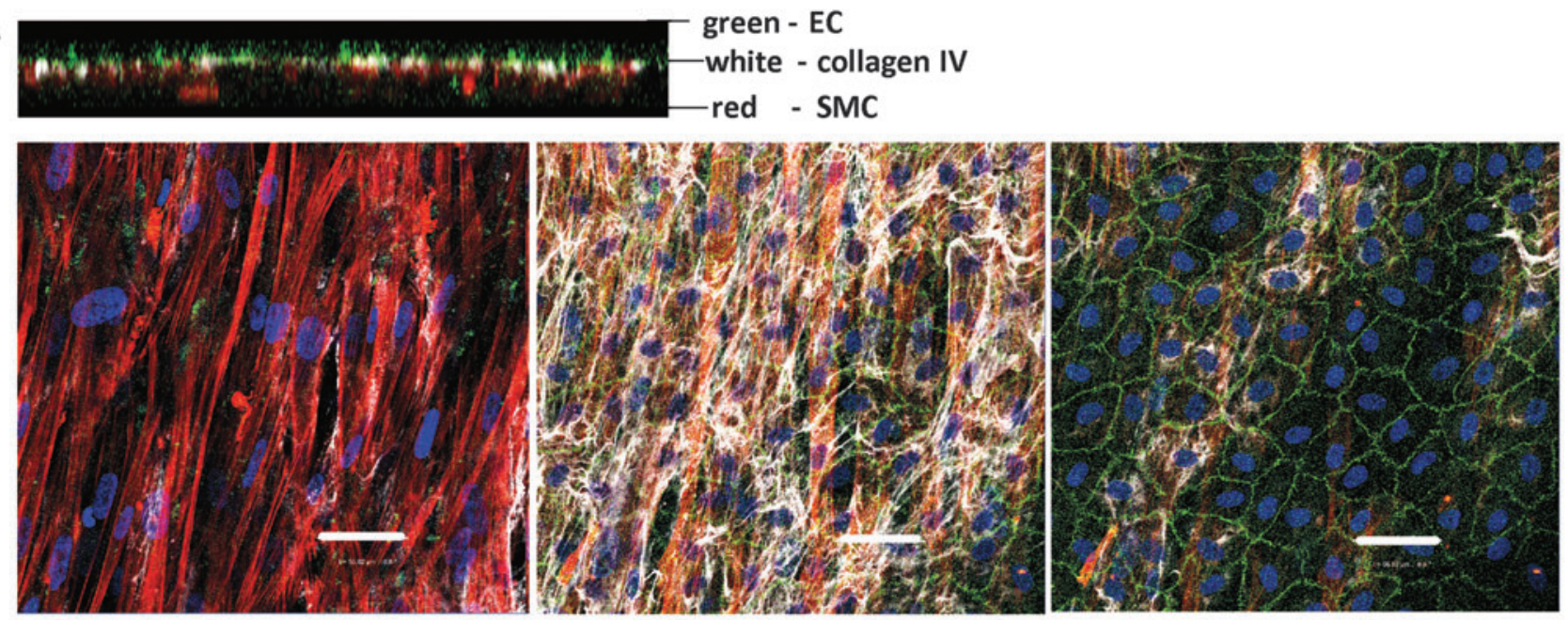

$4.1 \mu \mathrm{m}$

$10.2 \mu \mathrm{m}$

$12.3 \mu \mathrm{m}$

B
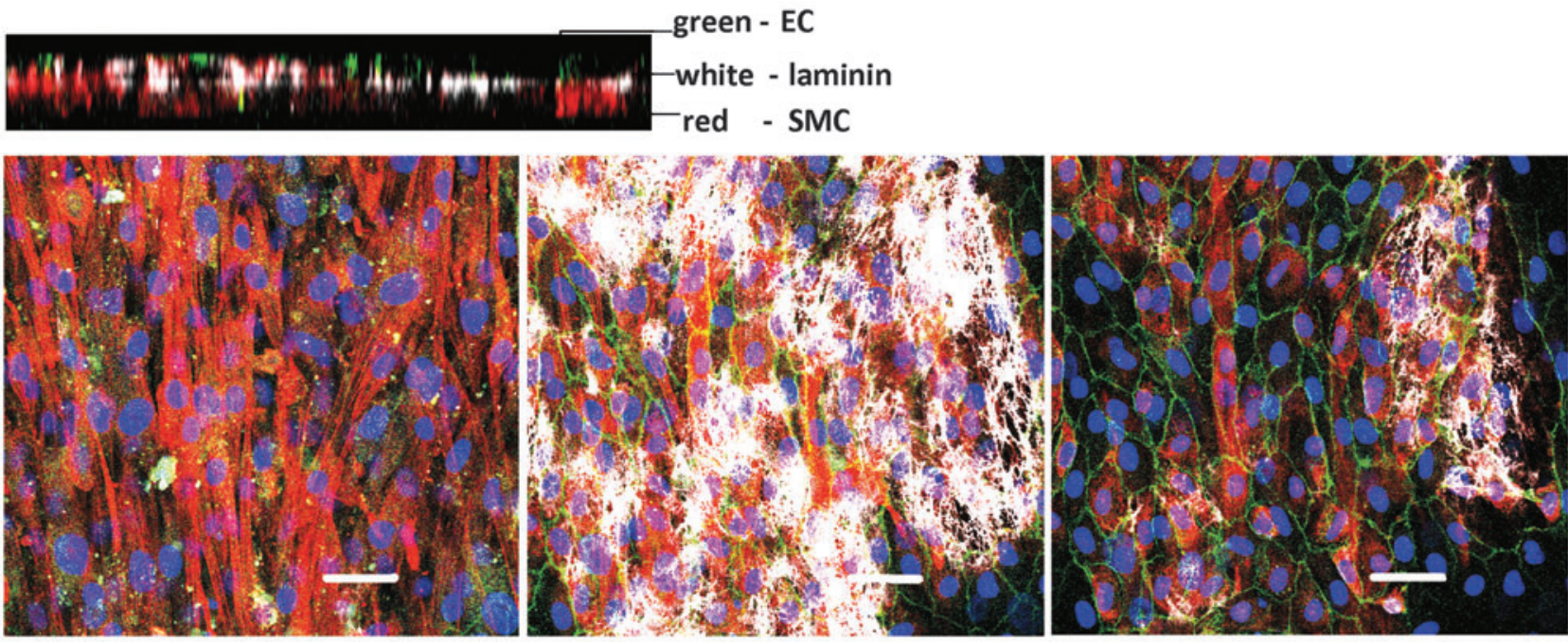

$4.6 \mu \mathrm{m}$

$8.0 \mu \mathrm{m}$

$10.3 \mu \mathrm{m}$

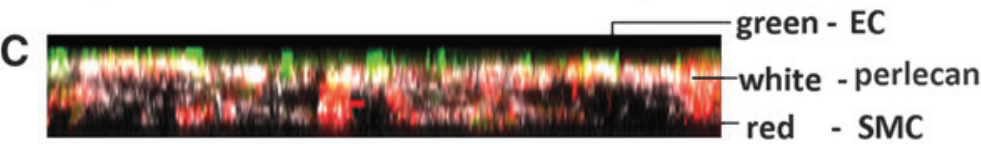

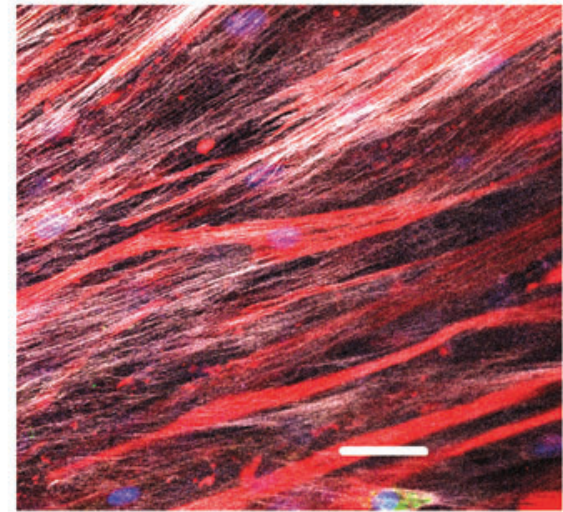

$1.3 \mu \mathrm{m}$

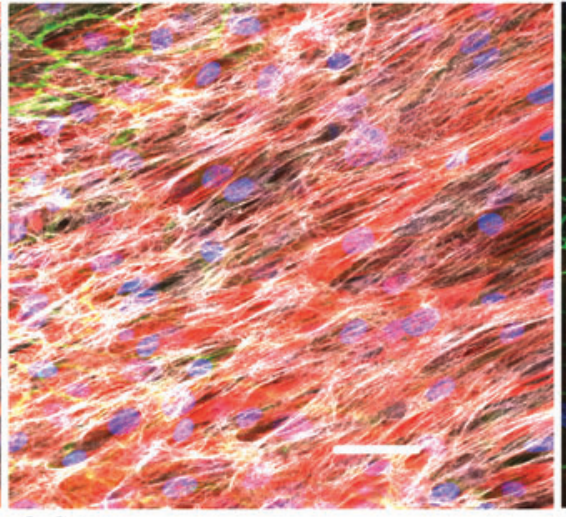

$10.6 \mu \mathrm{m}$

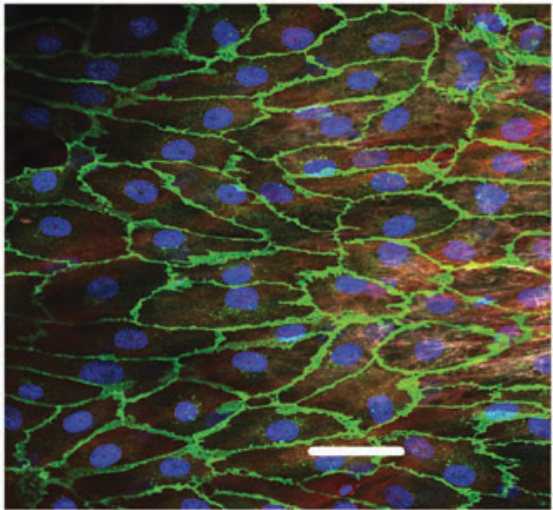

$17.2 \mu \mathrm{m}$

FIG. 4. The vascular basement membrane of the 3D SW-CC on day 7. Representative confocal images from a Z stack gallery at indicated distances from the bottom of the well along with the respective orthogonal cuts. The 3D SW-CC was fixed and stained for alpha-smooth muscle actin ( $r e d, \mathrm{SMC}$ ), VE-cadherin (green, EC), DAPI (blue, nuclei), and indicated matrix proteins [white, $(\mathbf{A})$ collagen IV, (B) laminin (C) perlecan]. Scale bar $=50 \mu \mathrm{m}$. DAPI, 4',6-diamidino-2-phenylindole. 
were negative for CD44. TGF- $\beta 1$-treated EC served as a positive control (Supplementary Fig. S2C). Figure 3D depicts the threedimensional reconstruction (lateral and frontal view) of the $\mathrm{EC}$ and SMC within the 3D SW-CC, which further demonstrates the clear separation of the cell layers.

\section{Vascular basement membrane matrix deposition in the $3 D S W-C C$}

The vascular basement membrane matrix functions as a thin boundary between different compartments of the vessel wall. Type-IV collagen and laminins are the major components of the vascular basement membrane. ${ }^{31-33}$ They selfassemble to form networks making up the extracellular matrix. Other components include heparan sulfate proteoglycans (e.g., perlecan), nidogens, osteonectin (SPARC), fibulins, collagen types VIII, XV, and XVIII, and thrombospondins. ${ }^{34}$ This matrix has mechanical properties, plays a role in regulating the morphology and phenotype of SMC, ${ }^{35}$ in regulating the gene expression of neighboring cells, and is important during vasculogenesis and wound healing. ${ }^{34,36}$ Hence, we verified the presence and location of collagen IV, laminin, and perlecan in the 3D SW-CC. On day 7, the collagen IV and laminin staining was restricted to a $2-3-\mu \mathrm{m}$-thin layer between SMC and EC. Collagen IV produced a cobweb-like
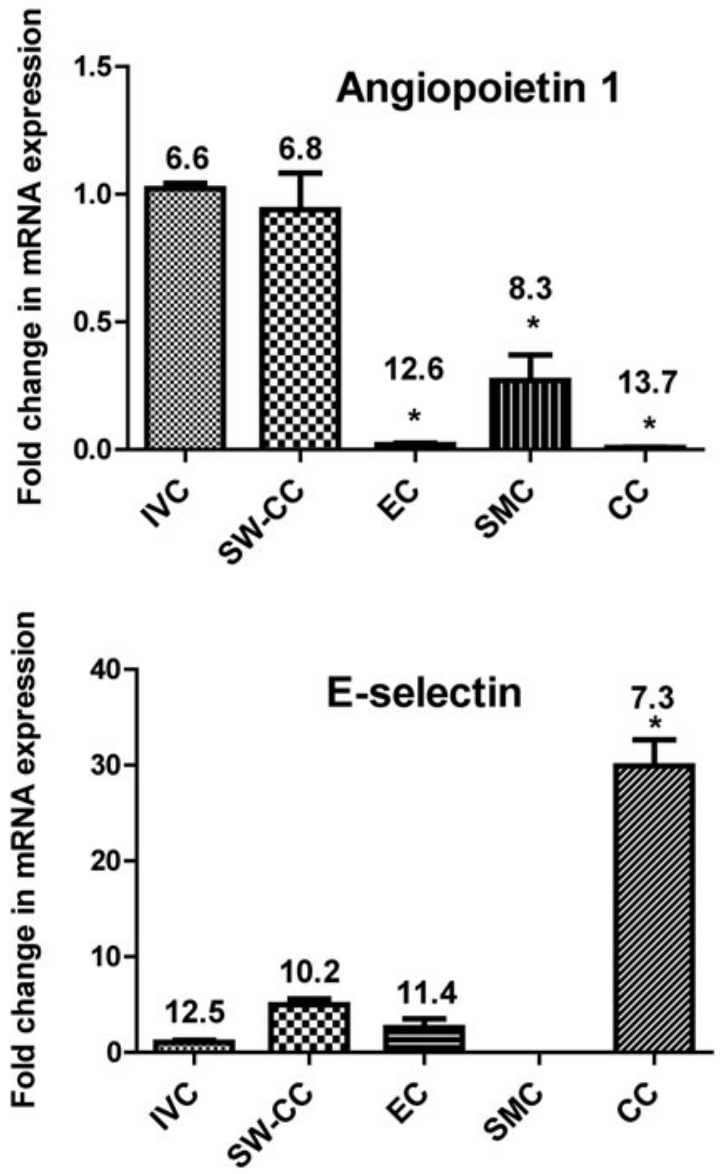

fibrillary network between SMC and EC (Fig. 4A and Supplementary Fig. S3A). Laminin showed a patchy distribution, distinct from of collagen IV (Fig. 4B and Supplementary Fig. S3B). It has been described previously that laminin polymerizes to form sheet-like nets or patches and collagen IV forms skeletal mesh-like polymeric arrays in vitro and in vivo ${ }^{37}$ similar to our results. Our confocal z-stack images show that differences in cell densities were not responsible for this patchy distribution of laminin. Perlecan (Fig. 4C and Supplementary Fig. S3C) was distributed as long thin continuous strands. Most of the perlecan localized at the interface of SMC and EC. However, in contrast to collagen IV and laminin, perlecan was also found intermingled with SMC reaching down to the bottom of the well. None of the three matrix proteins were found between EC.

These findings clearly indicate that $\mathrm{SMC}$ and $\mathrm{EC}$ within the 3D SW-CC rapidly produce their own extracellular interface similar to the vascular basement membrane matrix found in vivo. Collagen IV and laminins are known to promote the contractile SMC phenotype. ${ }^{26}$ Laminins are in direct contact with EC and SMC surfaces, they trap growth factors and control cellular functions like adhesion, proliferation, migration, and apoptosis. ${ }^{33,38}$ Laminins provide the substrate to which the basal side of the EC adheres through lamininspecific receptors. ${ }^{39}$ Heparan sulfate proteoglycans cooperate
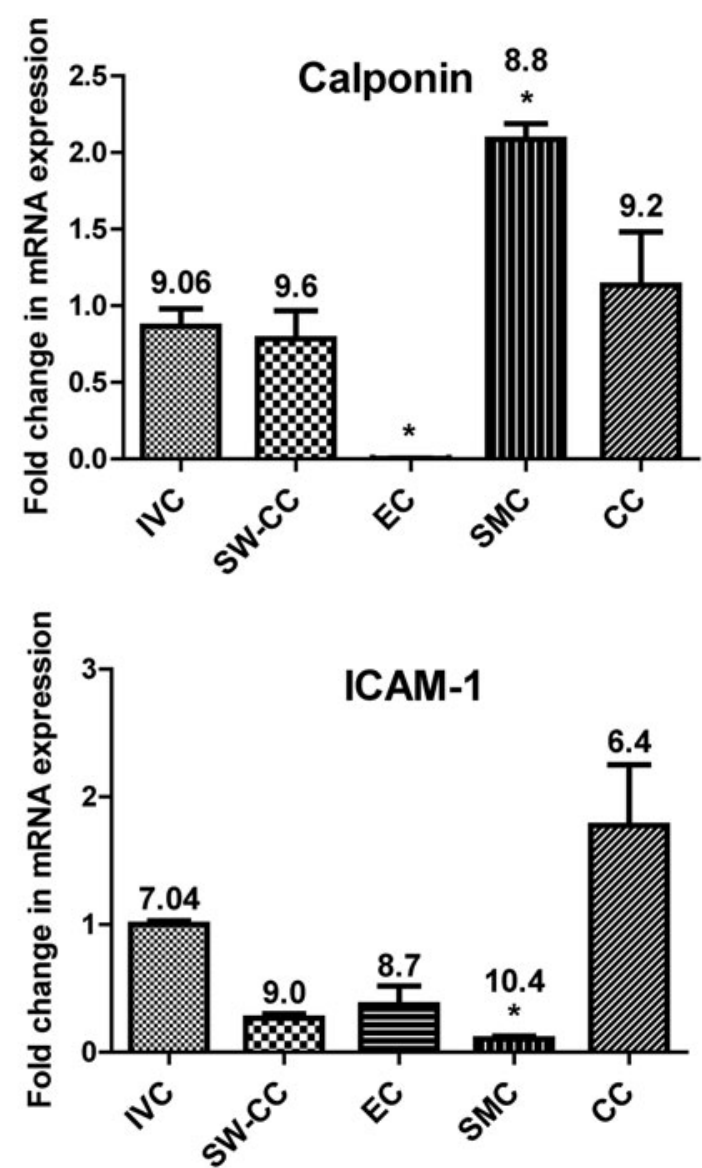

FIG. 5. Basal activation of the 3D SW-CC on day 7. mRNA expression of angiopoietin 1, calponin 1, E-selectin, and ICAM-1 in indicated cultures was determined by quantitative real-time PCR. Data were normalized to the corresponding values of a freshly isolated piece of mouse IVC. Bar graphs display mean \pm SD. $n=4, * p<0.05$, one-way ANOVA with Dunnett's multiple comparison test. Mean $\Delta C_{T}$ values are included for each sample group. IVC, inferior vena cava; mRNA, messenger RNA; PCR, polymerase chain reaction. 
with other matrix components to configure the structure, function, and stability of the basement membrane. ${ }^{40}$ The major heparan sulfate proteoglycan of the vascular matrix is the EC-derived perlecan, which is a potent regulator of vascular homeostasis. On vascular SMC, perlecan acts antimigratory and antiproliferative and attenuates proliferation and the migratory response to platelet-derived growth factor $\mathrm{BB}$ (PDGF-BB). ${ }^{41,42}$ Conversely, on EC, it promotes mitogenesis, ${ }^{43}$ aids in vessel wall repair after injury, and supports angiogenesis. ${ }^{44}$ Thus, the autogenously produced vascular basement membrane aids to the stability and quiescence of our 3D SW-CC.

\section{Differentiation and basal activation of the $3 D S W-C C$}

We first analyzed the basal mRNA expression of vessel wall stability markers. Angiopoietin 1 belongs to a family of secreted glycoproteins that play a pivotal role in vascular development and angiogenesis. Within the context of EC, angiopoietin 1 is essential for their interaction with the surrounding matrix. It controls EC permeability, regulates EC survival, and has anti-inflammatory functions. ${ }^{4-51}$ The fold changes in mRNA expression of SW-CC, EC and SMC monolayers, and CC (coculture made without the collagen I sandwich) shown in Figure 5 were normalized to freshly

\section{A}
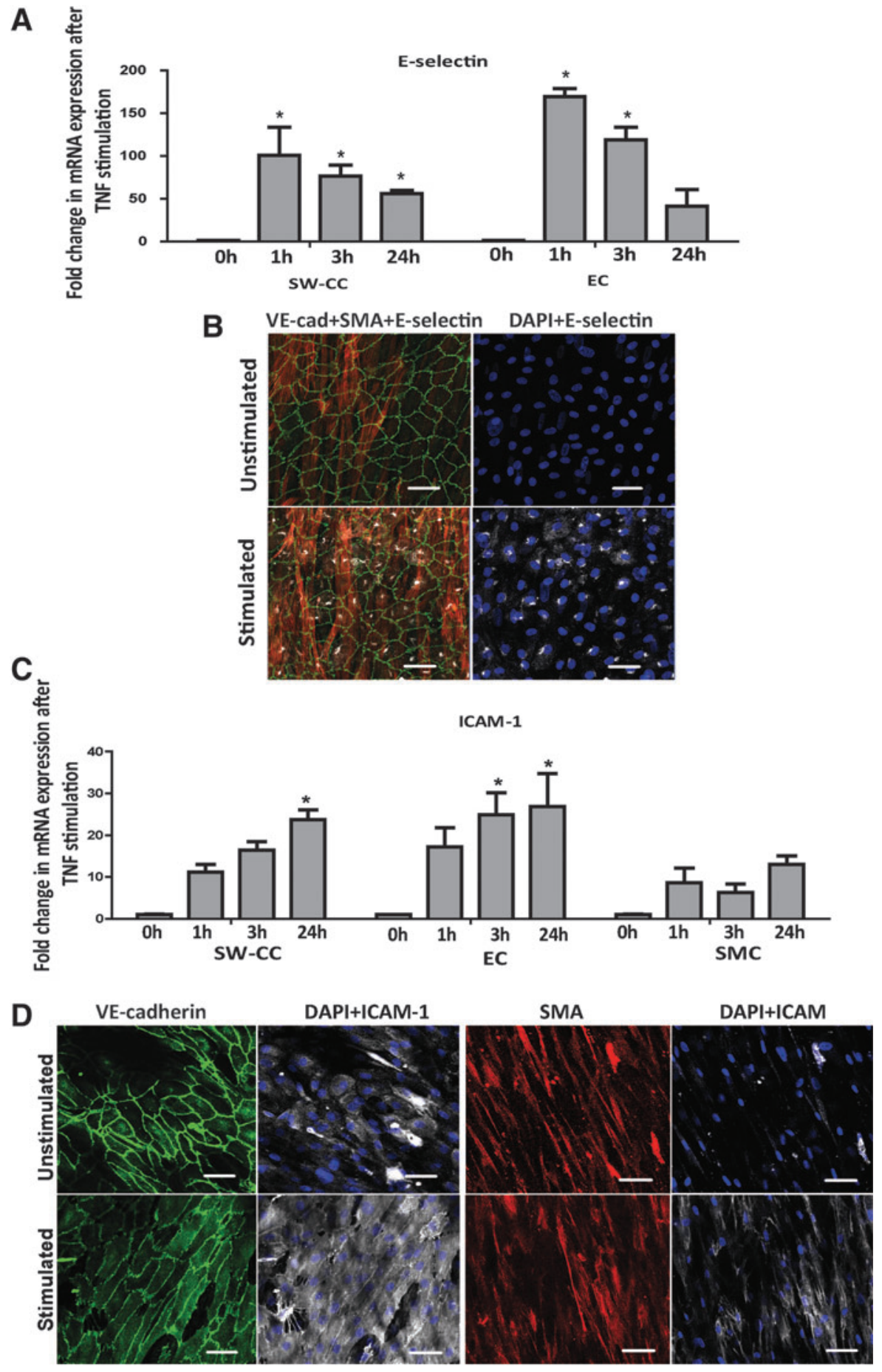

FIG. 6. TNF stimulation of the 3D SW-CC. Indicated cultures were stimulated with $10 \mathrm{ng} / \mathrm{mL}$ of TNF $\alpha$ for $0,1,6$, and $24 \mathrm{~h}$. Following lysis and mRNA isolation, E-selectin (A) and ICAM-1 (C) mRNA expressions were determined by quantitative real-time PCR. Values were normalized to the respective unstimulated condition $(0 \mathrm{~h})$. Bar graphs display mean \pm SD. $n=4$, * $p<0.05$, twoway ANOVA with Bonferroni post hoc test. Immunofluorescence images demonstrating E-selectin (B) and ICAM-1 (D) protein expressions after 4 and $18 \mathrm{~h}$ of TNF $\alpha$ stimulations, respectively. $\alpha-$ smooth muscle actin (red), VEcadherin (green), nuclei (blue), and E-selectin or ICAM-1 (white). Representative confocal images are shown $(20 \times$ magnification $)$, scale bar $=50 \mu \mathrm{m}$. TNF, tumor necrosis factor. 
isolated piece of mouse IVC. Angiopoietin 1 mRNA was present in SMC, but not in $\mathrm{EC}^{48}$ In the $\mathrm{SW}-\mathrm{CC}$, angiopoietin 1 mRNA expression was multiplied, up to a level found in IVC in vivo. The CC system without the collagen I sandwich, where EC were directly seeded on top of SMC, was unable to produce angiopoietin 1 mRNA. Calponin, a filamentassociated, actin-binding protein, is highly expressed in SMC that display a contractile phenotype. ${ }^{52,53}$ Its downregulation indicates a phenotype switch of SMC from contractile to secretory. ${ }^{54-56}$ The expression of comparable amounts of calponin mRNA in the IVC and in the SW-CC supports the morphologic observations (Figs. 2 and 3) that SMC in the SW-CC were contractile in phenotype.

We next analyzed basal mRNA expression of activation markers like E-selectin and ICAM-1. Quiescent EC express very low levels of E-selectin. ICAM-1 is constitutively expressed on EC and inducible on SMC. ${ }^{57-59}$ Values were normalized to those from a freshly isolated piece of mouse IVC. In the SW-CC as well as in EC cultures, E-selectin mRNA expression was marginally higher than in the IVC (Fig. 5). CT values were in the range of 27-29, indicating very low expression (B2M/GAPDH values were uniform across all
FIG. 7. Stimulation of the 3D SW-CC with activated platelets. Representative confocal images of the 3D SW-CC from a Z stack gallery at indicated distances from the bottom of the well shown along with the respective orthogonal cuts of (A) control 3D SW-CC on day 7, (B) 3D SW-CC after coculturing with platelets (ratio of 100:1) for $24 \mathrm{~h}$. Following fixation, cells were stained for $\alpha$-SMA (red), VE-cadherin (green), and CD41 for platelets (white). Scale bar $=50 \mu \mathrm{m}$.

(C) At indicated time points following the addition of platelets, cells were lysed, mRNA was isolated, and expression of E-selectin and ICAM-1 was determined by quantitative real-time PCR in indicated cultures. Expression levels were normalized to the respective unstimulated condition $(0 \mathrm{~h})$. Bar graphs display mean \pm SD. $n=4, * p<0.05$, two-way ANOVA with Bonferroni post hoc test.
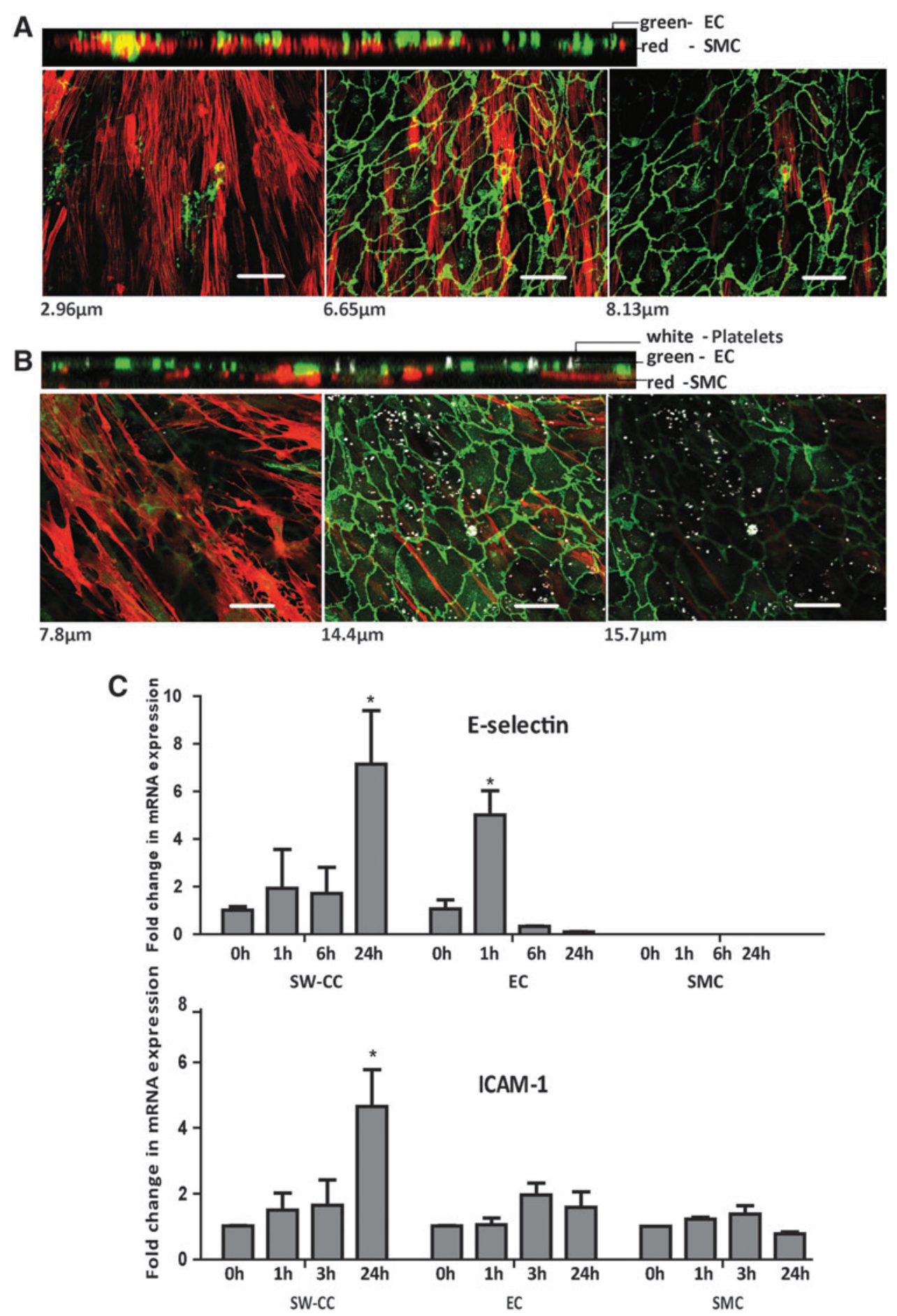
samples). This correlated to E-selectin protein expression, which was undetectable under baseline conditions by immunofluorescence (Fig. 6B). However, in the coculture without the collagen I sandwich (CC), EC were activated and expressed significant amounts of E-selectin mRNA. Others have reported that in such a direct $\mathrm{CC}$, SMC induce EC Eselectin in an IL-1- and IL-6-dependent manner. ${ }^{60}$ A similar result was obtained with ICAM-1. ICAM-1 mRNA expression was even lower in the SW-CC when compared to the IVC, probably due to ICAM-1 expression by resident fibroblasts or macrophages within the adventitia of the IVC, which are not present in the SW-CC.

\section{TNF $\alpha$ and platelet-induced activation of the 3D SW-CC}

We further analyzed the response of our 3D SW-CC to a proinflammatory cytokine, TNF $\alpha{ }^{61}$ For comparison, we selected a cellular activation signal by adding activated platelets to the SW-CC. Both, the EC monolayer and the 3D SW-CC, responded equally to TNF $\alpha$ stimulation by inducing E-selectin mRNA (after $1 \mathrm{~h}$ ) and protein (after $4 \mathrm{~h}$ ) expression (Fig. 6A, B). As expected, ICAM-1 mRNA (after $1 \mathrm{~h}$ ) and protein (after $18 \mathrm{~h}$ ) were induced in EC, SMC, and the 3D SW-CC once exposed to TNF $\alpha$ (Fig. 6C, D).

Activated platelets have been shown to induce endothelial E-selectin expression in a pathway involving platelet factor 4 and to induce ICAM-1 expression. ${ }^{62,63}$ Platelet-released factors induce proliferation, migration, and calponin downregulation in SMC, partly through platelet factor $4 .{ }^{64,65}$ When activated platelets were added to our 3D SW-CC, they adhered to the endothelial surfaces, but did not get in direct contact with the underlying SMC layer even after $24 \mathrm{~h}$ of coculture (Fig. 7B). Importantly, at this time point, the EC monolayer remained morphologically intact, but the underlying SMC had changed to a rhomboidal shape reminiscent of the secretory phenotype compared to the control (Fig. 7A). In addition, platelets induced significant amounts of E-selectin expression in the 3D SW-CC, although with a delay of $24 \mathrm{~h}$ compared with TNF $\alpha$, where peak levels were achieved with $1 \mathrm{~h}$ incubation. Initial E-selectin induction ( $1 \mathrm{~h}$ ) by platelets was higher in EC, and then declined, whereas in the 3D SW-CC maximum induction occurred at $24 \mathrm{~h}$. A similar picture was also seen with the induction of ICAM-1 (Fig. 7C). This delayed but significantly increased E-selectin and ICAM-1 mRNA expression of the 3D SW-CC by activated platelets after $24 \mathrm{~h}$ has to be attributed to an EC/SMC cross talk within the system.

\section{Conclusions}

We have thus engineered a modified 3D direct contact CC model (3D SW-CC) of EC on SMC, which mimics several important aspects of an in vivo blood vessel. EC form continuous monolayers and SMC display a contractile phenotype. EC and SMC layers were in close contact but clearly separated by an autogenously produced vascular basement membrane. The basal expression of activation and quiescence markers was comparable to that of a freshly isolated mouse IVC. The system can be activated by TNF $\alpha$ a proinflammatory cytokine. Moreover, the system is also suitable to analyze the cross talk between cellular elements as shown by the addition of platelets. Platelets elicit a distinct response pattern when added to the 3D SW-CC compared with EC or
SMC alone. Finally, this system is suitable for high-quality 3D confocal direct imaging and live cell imaging.

\section{Acknowledgment}

This work was supported by a grant from the Austrian Science Foundation SFB F5408-B21 to P.P.

\section{Disclosure Statement}

No competing financial interests exist.

\section{References}

1. Canham, P.B., et al. Measurements from light and polarised light microscopy of human coronary arteries fixed at distending pressure. Cardiovasc Res 23, 973, 1989.

2. Gasser, T.C., Ogden, R.W., and Holzapfel, G.A. Hyperelastic modelling of arterial layers with distributed collagen fibre orientations. J R Soc Interface 3, 15, 2006.

3. Lilly, B. We have contact: endothelial cell-smooth muscle cell interactions. Physiology (Bethesda) 29, 234, 2014.

4. Davis, S., et al. Isolation of angiopoietin-1, a ligand for the TIE2 receptor, by secretion-trap expression cloning. Cell 87, 1161, 1996.

5. Papapetropoulos, A., et al. Direct actions of angiopoietin-1 on human endothelium: evidence for network stabilization, cell survival, and interaction with other angiogenic growth factors. Lab Invest 79, 213, 1999.

6. Fukuhara, S., et al. Angiopoietin-1/Tie2 receptor signaling in vascular quiescence and angiogenesis. Histol Histopathol 25, 387, 2010.

7. Hellstrom, M., et al. Role of PDGF-B and PDGFR-beta in recruitment of vascular smooth muscle cells and pericytes during embryonic blood vessel formation in the mouse. Development 126, 3047, 1999.

8. Hoeben, A., et al. Vascular endothelial growth factor and angiogenesis. Pharmacol Rev 56, 549, 2004.

9. Pepper, M.S. Transforming growth factor-beta: vasculogenesis, angiogenesis, and vessel wall integrity. Cytokine Growth Factor Rev 8, 21, 1997.

10. Liu, Y., et al. Edg-1, the G protein-coupled receptor for sphingosine-1-phosphate, is essential for vascular maturation. J Clin Invest 106, 951, 2000.

11. Purcell, C., Tennant, M., and McGeachie, J. Neo-intimal hyperplasia in vascular grafts and its implications for autologous arterial grafting. Ann R Coll Surg Engl 79, 164, 1997.

12. Kornowski, R., et al. In-stent restenosis: contributions of inflammatory responses and arterial injury to neointimal hyperplasia. J Am Coll Cardiol 31, 224, 1998.

13. Kipshidze, N., et al. Role of the endothelium in modulating neointimal formation: vasculoprotective approaches to attenuate restenosis after percutaneous coronary interventions. J Am Coll Cardiol 44, 733, 2004.

14. Rivard, A., and Andres, V. Vascular smooth muscle cell proliferation in the pathogenesis of atherosclerotic cardiovascular diseases. Histol Histopathol 15, 557, 2000.

15. Mitra, A.K., Gangahar, D.M., and Agrawal, D.K. Cellular, molecular and immunological mechanisms in the pathophysiology of vein graft intimal hyperplasia. Immunol Cell Biol 84, 115, 2006.

16. Rose, S.L., and Babensee, J.E. Complimentary endothelial cell/ smooth muscle cell co-culture systems with alternate smooth muscle cell phenotypes. Ann Biomed Eng 35, 1382, 2007. 
17. Wallace, C.S., Champion, J.C., and Truskey, G.A. Adhesion and function of human endothelial cells co-cultured on smooth muscle cells. Ann Biomed Eng 35, 375, 2007.

18. Fillinger, M.F., et al. The effect of endothelial cell coculture on smooth muscle cell proliferation. J Vasc Surg 17, 1058; discussion 1067, 1993.

19. van Buul-Wortelboer, M.F., et al. Reconstitution of the vascular wall in vitro. A novel model to study interactions between endothelial and smooth muscle cells. Exp Cell Res 162, 151, 1986.

20. Korff, T., et al. Blood vessel maturation in a 3-dimensional spheroidal coculture model: direct contact with smooth muscle cells regulates endothelial cell quiescence and abrogates VEGF responsiveness. FASEB J 15, 447, 2001.

21. Petzelbauer, P., et al. IL-8 and angiogenesis: evidence that human endothelial cells lack receptors and do not respond to IL-8 in vitro. Cytokine 7, 267, 1995.

22. Leik, C.E., et al. Isolation and culture of arterial smooth muscle cells from human placenta. Hypertension 43, 837, 2004.

23. Rajan, N., et al. Preparation of ready-to-use, storable and reconstituted type I collagen from rat tail tendon for tissue engineering applications. Nat Protoc 1, 2753, 2006.

24. Artym, V. V. and Matsumoto, K. Imaging Cells in ThreeDimensional Collagen Matrix. Current Protocols in Cell Biology. 48:10.18:10.18.1-10.18.20, 2010.

25. Assinger, A., et al. Human cytomegalovirus-platelet interaction triggers toll-like receptor 2-dependent proinflammatory and proangiogenic responses. Arterioscler Thromb Vasc Biol 34, 801, 2014.

26. Rensen, S.S., Doevendans, P.A., and van Eys, G.J. Regulation and characteristics of vascular smooth muscle cell phenotypic diversity. Neth Heart J 15, 100, 2007.

27. Ponticos, M., et al. Regulation of collagen type I in vascular smooth muscle cells by competition between $\mathrm{Nkx} 2.5$ and deltaEF1/ZEB1. Mol Cell Biol 24, 6151, 2004.

28. Stacey, D.W. Cyclin D1 serves as a cell cycle regulatory switch in actively proliferating cells. Curr Opin Cell Biol 15, 158, 2003.

29. Birukov, K.G., et al. Expression of calponin in rabbit and human aortic smooth muscle cells. Cell Tissue Res 266, 579, 1991.

30. Medici, D. Endothelial-mesenchymal transition in regenerative medicine. Stem Cells Int 2016, 6962801, 2016.

31. Timpl, R., and Brown, J.C. Supramolecular assembly of basement membranes. Bioessays 18, 123, 1996.

32. Tanjore, H., and Kalluri, R. The role of type IV collagen and basement membranes in cancer progression and metastasis. Am J Pathol 168, 715, 2006.

33. Aumailley, M., and Smyth, N. The role of laminins in basement membrane function. J Anat 193, 1, 1998.

34. Wagenseil, J.E., and Mecham, R.P. Vascular extracellular matrix and arterial mechanics. Physiol Rev 89, 957. 2009.

35. Hungerford, J.E., and Little, C.D. Developmental biology of the vascular smooth muscle cell: building a multilayered vessel wall. J Vasc Res 36, 2, 1999.

36. Hayden, M.R., Sowers, J.R., and Tyagi, S.C. The central role of vascular extracellular matrix and basement membrane remodeling in metabolic syndrome and type 2 diabetes: the matrix preloaded. Cardiovasc Diabetol 4, 9, 2005.

37. Farquhar, M.G. The Glomerular Basement Membrane. In: ED, H., (ed.). Cell biology of extracellular matrix, 2nd edn. New York: Plenum Press, 1991, pp. 365-418.
38. Terranova, V.P., Rohrbach, D.H., and Martin, G.R. Role of laminin in the attachment of PAM 212 (epithelial) cells to basement membrane collagen. Cell 22, 719, 1980.

39. Languino, L.R., et al. Endothelial cells use alpha 2 beta 1 integrin as a laminin receptor. J Cell Biol 109, 2455, 1989.

40. Sarrazin S, Lamanna WC, Esko JD. Heparan sulfate protoglycans. Cold Spring Harb Perspect Biol 3, a004952, 2011.

41. Nugent, M.A., Karnovsky, M.J., and Edelman, E.R. Vascular cell-derived heparan sulfate shows coupled inhibition of basic fibroblast growth factor binding and mitogenesis in vascular smooth muscle cells. Circ Res 73, 1051, 1993.

42. Garl, P.J., et al. Perlecan-induced suppression of smooth muscle cell proliferation is mediated through increased activity of the tumor suppressor PTEN. Circ Res 94, 175, 2004.

43. Aviezer, D., et al. Perlecan, basal lamina proteoglycan, promotes basic fibroblast growth factor-receptor binding, mitogenesis, and angiogenesis. Cell 79, 1005, 1994.

44. Iozzo, R.V., and San Antonio, J.D. Heparan sulfate proteoglycans: heavy hitters in the angiogenesis arena. J Clin Invest 108, 349, 2001.

45. Gavard, J., Patel, V., and Gutkind, J.S. Angiopoietin-1 prevents VEGF-induced endothelial permeability by sequestering Src through mDia. Dev Cell 14, 25, 2008.

46. Thurston, G., et al. Leakage-resistant blood vessels in mice transgenically overexpressing angiopoietin-1. Science 286, 2511, 1999.

47. Papapetropoulos, A., et al. Angiopoietin-1 inhibits endothelial cell apoptosis via the Akt/survivin pathway. J Biol Chem 275, 9102, 2000.

48. Kim, I., et al. Angiopoietin-1 regulates endothelial cell survival through the phosphatidylinositol $3^{\prime}$-Kinase/Akt signal transduction pathway. Circ Res 86, 24, 2000.

49. Gamble, J.R., et al. Angiopoietin-1 is an antipermeability and anti-inflammatory agent in vitro and targets cell junctions. Circ Res 87, 603, 2000.

50. Pizurki, L., et al. Angiopoietin-1 inhibits endothelial permeability, neutrophil adherence and IL-8 production. Br J Pharmacol 139, 329, 2003.

51. Suri, C., et al. Requisite role of angiopoietin-1, a ligand for the TIE2 receptor, during embryonic angiogenesis. Cell 87, 1171, 1996.

52. Duband, J.L., et al. Calponin and SM 22 as differentiation markers of smooth muscle: spatiotemporal distribution during avian embryonic development. Differentiation 55, 1, 1993.

53. Takahashi, K., Hiwada, K., and Kokubu, T. Vascular smooth muscle calponin. A novel troponin T-like protein. Hypertension 11, 620, 1988.

54. Long, X., et al. Smooth muscle calponin: an unconventional CArG-dependent gene that antagonizes neointimal formation. Arterioscler Thromb Vasc Biol 31, 2172, 2011.

55. Yang, H.M., et al. PPARgamma modulates vascular smooth muscle cell phenotype via a protein kinase Gdependent pathway and reduces neointimal hyperplasia after vascular injury. Exp Mol Med 45, e65, 2013.

56. Cordes, K.R., et al. miR-145 and miR-143 regulate smooth muscle cell fate and plasticity. Nature 460, 705, 2009.

57. Leeuwenberg, J.F., et al. E-selectin and intercellular adhesion molecule- 1 are released by activated human endothelial cells in vitro. Immunology 77, 543, 1992.

58. Braun, M., et al. Cellular adhesion molecules on vascular smooth muscle cells. Cardiovasc Res 41, 395, 1999. 
59. Springer, T.A. Adhesion receptors of the immune system. Nature 346, 425, 1990.

60. Chiu, J.J., et al. Mechanisms of induction of endothelial cell E-selectin expression by smooth muscle cells and its inhibition by shear stress. Blood 110, 519, 2007.

61. Pober, J.S., and Cotran, R.S. Cytokines and endothelial cell biology. Physiol Rev 70, 427, 1990.

62. $\mathrm{Yu}, \mathrm{G}$., et al. Endothelial expression of E-selectin is induced by the platelet-specific chemokine platelet factor 4 through LRP in an NF-kappaB-dependent manner. Blood 105, 3545, 2005.

63. Gawaz, M., et al. Activated platelets induce monocyte chemotactic protein-1 secretion and surface expression of intercellular adhesion molecule-1 on endothelial cells. Circulation 98, 1164, 1998.

64. Jawien, A., et al. Platelet-derived growth factor promotes smooth muscle migration and intimal thickening in a rat model of balloon angioplasty. J Clin Invest 89, 507, 1992.
65. Shi, G., et al. Platelet factor 4 mediates vascular smooth muscle cell injury responses. Blood 121, 4417, 2013.

Address correspondence to: Peter Petzelbauer, MD

Skin and Endothelium Research Division (SERD)

Department of Dermatology Medical University of Vienna Lazarettgasse 14 A-1090 Vienna

Austria

E-mail: peter.petzelbauer@meduniwien.ac.at

Received: July 19, 2016

Accepted: November 28, 2016

Online Publication Date: December 29, 2016 